\title{
High-fat-diet-induced weight gain ameliorates bone loss without exacerbating $A \beta P P$ processing and cognition in female APP/PS1 mice
}

\author{
Yunhua Peng ${ }^{1}$, Jing Liu ${ }^{1}$, Ying Tang ${ }^{1}$, Jianshu Liu ${ }^{2}$,Tingting Han ${ }^{2}$, Shujun Han ${ }^{1}$, Hua Li ${ }^{1}$, Chen Hou ${ }^{1}$, \\ Jiankang Liu ${ }^{1}$ and Jiangang Long ${ }^{1}$ *
}

\author{
Center for Mitochondrial Biology and Medicine, The Key Laboratory of Biomedical Information Engineering of Ministry of Education, School of Life Science and \\ Technology and Frontier Institute of Science and Technology, Xi'an Jiaotong University, Xi'an, China \\ ${ }^{2}$ Shaanxi Translational Center for Functional Foods, Xi'an, China
}

\section{Edited by:}

Rena Li, Roskamp Institute, USA

Reviewed by:

Nicolas Blondeau, Centre National de la Recherche Scientifique, France Jie Cui, Roskamp Institute, USA

*Correspondence:

Jiangang Long, Center for

Mitochondrial Biology and Medicine,

School of Life Science and

Technology, Xi'an Jiaotong University,

No. 28, Xianning West Road, Xi'an,

Shaanxi 710049, China

e-mail: jglong@mail.xjtu.edu.cn
Osteoporosis is negatively correlated with body mass, whereas both osteoporosis and weight loss occur at higher incidence during the progression of Alzheimer's disease (AD) than the age-matched non-dementia individuals. Given that there is no evidence that being overweight is associated with AD-type cognitive dysfunction, we hypothesized that moderate weight gain might have a protective effect on the bone loss in $A D$ without exacerbating cognitive dysfunction. In this study, feeding a high-fat diet (HFD, $45 \%$ calorie from fat) to female APP/PS1 transgenic mice, an AD animal model, induced weight gain. The bone mineral density, microarchitecture, and biomechanical properties of the femurs were then evaluated. The results showed that the middle-aged female APP/PS1 transgenic mice were susceptible to osteoporosis of the femoral bones and that weight gain significantly enhanced bone mass and mechanical properties. Notably, HFD was not detrimental to brain insulin signaling and A $\beta P P$ processing, as well as to exploration ability and working, learning, and memory performance of the transgenic mice measured by T maze and Morris water maze, compared with the mice fed a normal-fat diet ( $10 \%$ calorie from fat). In addition, the circulating levels of leptin but not estradiol were remarkably elevated in HFDtreated mice. These results suggest that a body weight gain induced by the HFD feeding regimen significantly improved bone mass in female APP/PS1 mice with no detriments to exploration ability and spatial memory, most likely via the action of elevated circulating leptin.

Keywords: Alzheimer's disease, osteoporosis, weight gain, bone mineral density, leptin

\section{INTRODUCTION}

Alzheimer's disease (AD), the most common type of dementia, is defined as "the disease or injury which initiated the train of events leading directly to death" by World Health Organization (Alzheimer's Association, 2014). Growing incidence rate of AD worldwide makes it emergent to deal with its complications, such as osteoporosis (Bredesen and John, 2013). Some studies have indicated that low bone mineral density (BMD) or an increased rate of BMD loss is associated with a higher risk of $\mathrm{AD}$ (Tan et al., 2005; Zhou et al., 2011). Epidemiology studies also show that AD itself is an independent risk factor for bone impairment (Sato et al., 1998; Weller and Schatzker, 2004; Loskutova et al., 2009), particularly in postmenopausal females (Andersen et al., 1999; Yoshimura et al., 2005). More importantly, in patient with $\mathrm{AD}$, the progression of osteoporosis is correlated with the $\mathrm{AD}$ pathogenesis (Lee et al., 2012).

It is evidenced that low body mass index (BMI) is associated with osteoporosis (Felson et al., 1993; Tremollieres et al., 1993; Ravn et al., 1999; De Laet et al., 2005), while obese individuals generally exhibit high BMD and bone strength (Reid et al., 1992; Khosla et al., 1996; Reid, 2002; Andersen et al., 2014; Johansson et al., 2014). Patients with AD exhibit a significant weight loss compared to the age-matched normal controls (White et al., 1996, 1998; Cronin-Stubbs et al., 1997; Stewart et al., 2005). There is no debate that being severely obese (BMI > 40) increases the risk for many illnesses and even increases mortality. However, the moderate overweight $(25<\mathrm{BMI}<30)$ showed a protective effect of lowering the mortality (Flegal et al., 2013; Couzin-Frankel, 2014; Solon-Biet et al., 2014), and some evidences suggest that being overweight is not associated with $\mathrm{AD}$-type cognitive dysfunction (Kalmijn et al., 2000; Kivipelto et al., 2005). Thus, we hypothesized that moderate weight gain may improve the bone loss without exacerbating cognitive dysfunction in AD.

As one approach leading to weight gain, an extremely high-fat diet (HFD, $60 \%$ calorie from fat) was previously shown to induce a remarkable brain insulin resistance as well as spatial memory impairment in a normal mouse or a transgenic mouse model of AD (Ho et al., 2004; Moroz et al., 2008; Leboucher et al., 2013). In contrast, a moderate HFD ( $45 \%$ calorie from fat) caused little impairment in central insulin signaling and spatial memory (Mielke et al., 2006; McNeilly et al., 2012), although an operant bar-pressing task appeared to be capable of distinguishing 
the mice fed a moderate HFD from the vehicle controls (Mielke et al., 2006; McNeilly et al., 2011). Therefore, in this study, we induced a body weight gain in female APP/PS1 transgenic mice by feeding a moderate HFD ( $45 \%$ calorie from fat) to investigate the bone remodeling and the cognitive function. We found that severe femoral bone loss occurred in this transgenic mouse model of $\mathrm{AD}$, and the body weight gain induced by the HFD greatly improved bone mass and mechanic properties. However, cerebral insulin signaling, A $\beta P P$ processing, exploration ability, and spatial learning and memory were not deteriorated in transgenic mice fed HFD compared with the transgenic mice fed the control diet ( $10 \%$ calorie from fat). Our results suggested that the body weight management deserves to be evaluated in individuals with $\mathrm{AD}$, especially those who experience progressive weight loss and osteoporosis.

\section{MATERIALS AND METHODS ANIMALS}

The APPswe/PS1dE9 (APP/PS1) transgenic mice express both human presenilin 1 (A246E variant) and a chimeric amyloid precursor protein (APPswe) under direction of the mouse prion protein promoter, and on the $\mathrm{C} 57 \mathrm{BL} / 6 \mathrm{~J}$ background (Borchelt et al., 1997). Three-month-old APP/PS1 female transgenic mice and non-transgenic littermates (C57BL/6 mice) were used for this study. The mice were purchased from Nanjing Biomedical Research Institute of Nanjing University (Nanjing, Jiangsu, China) and housed at $23-25^{\circ} \mathrm{C}$ with $60 \%$ humidity under $12: 12 \mathrm{~h}$ light:dark cycles, with free access to food and water throughout the experiment. The mice were divided into three groups: wildtype mice (C57BL/6 group, $n=10)$, APP/PS1 transgenic mice (APP/PS1 group, $n=12$ ), and APP/PS1 transgenic mice fed the HFD (APP/PS1 + HFD group, $n=11)$. During the 6 months of feeding, the mice consumed ad libitum either a control purified diet ( $10 \%$ calorie from fat) for the C57BL/6 group and APP/PS1 group, or an HFD (45\% calorie from fat) for APP/PS1 + HFD group. The composition of each diet and the fatty acid profile of each diet are listed in Table S1 in Supplementary Material. The detailed formula of each fat diet is given in Table S2 in Supplementary Material. The body weights were recorded weekly. All the experimental procedures followed the Guide for the Care and Use of Laboratory Animals: Eighth Edition, ISBN-10:0-309-153964 , and the animal protocol was approved by the animal ethics committee of School of Life Science, Xi'an Jiaotong University.

At 8.5 months of age, the mice were subjected to a T-shaped maze on 1 day. Three days later, the mice were subjected to a water maze every day for 7 days. The mice were sacrificed by decapitation 3 days after the end of the water maze testing, so that the age of mice when they were sacrificed was 9 months. The brain, liver, and serum were harvested, as well as the femurs in both hindlimbs. The left femur was stored in saline at $4^{\circ} \mathrm{C}$ for the measurement of mechanical parameters. The right femur was fixed in $10 \%$ formaldehyde for micro-CT scanning.

\section{MEASUREMENTS OF EXPLORATION ABILITY, WORKING, LEARNING} AND MEMORY PERFORMANCE WITH THE T-MAZE AND WATER MAZE

The T-shaped maze was constructed with one start arm and two goal arms, all with a length of $30 \mathrm{~cm}$, width of $10 \mathrm{~cm}$, and height of $20 \mathrm{~cm}$. Spontaneous alternation of the T-maze is based on the assumption that the mouse always prefers to explore the new arm rather than the familiar arm (Gerlai, 1998). The tested mouse was first placed in the start arm of the T-maze. The mouse was then free to choose to enter either the left or the right goal arm (Reisel et al., 2002; Deacon and Rawlins, 2005). The choices of each mouse were recorded to calculate the percentage of alternations for eight trials with a 15-min interval between each trail. The latency time to reach the goal arm for each mouse was also recorded.

The Morris water maze tests were conducted in a diameter of $120 \mathrm{~cm}$ round tank filled with opaque water. The water was kept at $25^{\circ} \mathrm{C}$ and surrounded by dark walls containing geometric designs as visual cues. The hidden 7.5 diameter platform was submerged $0.5 \mathrm{~cm}$ below the water surface. The day before the first testing day, each mouse was allowed to swim freely in the tank for $90 \mathrm{~s}$. On the first day of the training, each mouse was placed in two different quadrants of the pool and was required to find the hidden platform for two trials with a maximum of $120 \mathrm{~s}$ for each trial. For the next 5 days, each mouse was placed in three different quadrants of the pool and allowed a maximum of $120 \mathrm{~s}$ to find the submerged platform. During the consecutive 6 days of training, if the mice failed to find the platform within $120 \mathrm{~s}$, they were physically guided to it and allowed to remain on the platform for $20 \mathrm{~s}$. On the seventh day that after 6 days of training, the platform was removed and mice were tested with a probe trial. The total time for each mouse was $45 \mathrm{~s}$. The performance in all tasks (escape latency to platform and distance to target quadrant during training phase; mean crossings on platform during probe trial) was recorded using a computer-based video tracking system (Vorhees and Williams, 2006).

\section{MEASUREMENT OF BRAIN A $\beta$}

The cortex was dissected and homogenized in ice-cold guanidine buffer ( $5 \mathrm{M}$ guanidine $\mathrm{HCl} / 50 \mathrm{mM}$ Tris $\mathrm{HCl}, \mathrm{pH} 8.0$ ) containing protease inhibitor mixture $(5 \mathrm{mM}$ sodium pyrophosphate, $1 \mathrm{mM}$ $\beta$-glycerolphosphate, $1 \mathrm{mM} \mathrm{Na} \mathrm{VO}_{4}, 1 \mathrm{mM}$ EDTA, and $1 \mu \mathrm{g} / \mathrm{ml}$ leupetin). The amounts of soluble $A \beta_{40}$ and $A \beta_{42}$ in brain cortical homogenates were determined by ELISA kits for $A \beta_{40}$ and $A \beta_{42}$ (Invitrogen, Camarillo, CA, USA), respectively, according to the manufacturer's instructions. In brief, $50 \mu l$ standards of known human $A \beta_{40}$ or $A \beta_{42}$ and the tested samples were added to the wells pre-coated with $\mathrm{NH}_{2}$-terminus of human $\mathrm{A} \beta$. Then, $50 \mu \mathrm{l}$ human $A \beta_{40}$ or $A \beta_{42}$ detection antibody solution was added into each well. The standards and samples were detected with horseradish peroxidase (HRP)-labeled anti-rabbit antibodies for the $\mathrm{COOH}$-terminus of the $1-40 \mathrm{~A} \beta$ or $1-42 \mathrm{~A} \beta$ sequence. The reactions were stopped by adding $100 \mu \mathrm{l}$ stop solution. The optical density (OD) at a wavelength of $450 \mathrm{~nm}$ was measured by FlexStation 3 microplate reader (Molecular Devices, Sunnyvale, CA, USA). The protein concentrations of the homogenates were determined using the $B C A$ method, and $A \beta_{40}$ and $A \beta_{42}$ were expressed as pg $A \beta_{40}$ or $A \beta_{42} / \mathrm{mg}$ protein.

\section{WESTERN BLOT}

The brain samples were lysed with Western and IP lysis buffer (Beyotime, Haimen, Jiangsu, China) and centrifuged at 13,000 g for $15 \mathrm{~min}$. The protein concentrations were determined using the BCA protein assay kit, and equal amounts of each protein 
(10 $\mu \mathrm{g})$ were subjected to sodium dodecyl sulfate polyacrylamide gel electrophoresis (SDS-PAGE), transferred to pure nitrocellulose membranes (PerkinElmer Life Sciences, Boston, MA, USA), and blocked with 5\% non-fat milk in Tris-buffered saline Tween20 (TBST) buffer. The membranes were incubated with primary antibodies (diluted by $1: 1,000$ to $1: 10,000$ ) for $3 \mathrm{~h}$ at room temperature. The antibodies against $\mathrm{A} \beta \mathrm{PP}, \mathrm{AKT}, \mathrm{p}-\mathrm{AKT}$, GSK $3 \beta$, and p-GSK3 $\beta$ were purchased from Cell Signaling Technology (Danvers, MA, USA), the $\mathrm{A} \beta$ antibody anti-6E10 was from Covance (Dedham, MA, USA), and the antibody against actin was from Invitrogen (Carlsbad, CA, USA). The membranes were subsequently incubated with anti-rabbit or antimouse antibodies for $1 \mathrm{~h}$ at room temperature. Chemiluminescent detection was performed using the Pierce ECL Western blotting substrate, and the signals were analyzed using Quantity One software.

\section{FEMUR MECHANICAL PROPERTY TESTING}

The mechanical properties of the femurs were determined using a three-point bending test that fractured the middle of the femoral region. The round-surfaced cross-head probe of a servo-controlled electromechanical testing system (Instron 5567, Canton, MA, USA) contacted the medial femur surface at its longitudinal midpoint within a $10 \mathrm{~mm}$ loading span. Loading speed was applied at $1 \mathrm{~mm} / \mathrm{min}$, and the load-deformation curve was recorded for calculation of elastic stress, elastic modulus, elastic force and ultimate force to fracture, energy absorption, and stiffness. The femur length was measured using digital calipers. The maximum and minimum outer and inner diameters of the fractured section were also measured using digital calipers for calculation of the second moment of inertia. The elastic force was the maximum load of the elastic (linear) region of the load-deformation curve. The ultimate force was the maximum load when the fracture occurred, which is defined as the height of the curve. Energy absorption was calculated as the product of load and displacement, defined as the area under the elastic region of the curve. Stiffness was calculated as the slope of the elastic region of the curve. The second moment of inertia $(J)$, elastic stress $\left(\sigma_{\varphi}\right)$, and elastic modulus $(E)$ were calculated according to the formulas below (Jämsä et al., 1998; Turner, 2002; Akhter et al., 2004; Bonnet et al., 2007; Yang et al., 2009).

$$
\begin{aligned}
J & =\frac{B H^{3}-b h^{3}}{64} \pi \\
\sigma_{\varphi} & =\frac{F_{\mathrm{p}}-H \times L}{8 \times J} \\
E & =\frac{F_{\mathrm{p}}-L^{3}}{48 \times d_{\mathrm{p}} \times J}
\end{aligned}
$$

where $F_{\mathrm{p}}$ is the difference between the highest and lowest loads of the elastic part of the load-displacement curve; $d_{\mathrm{p}}$ is the difference between the maximum and minimum displacements of the elastic part of the load-displacement curve; $L$ is the span length between two support points $(10 \mathrm{~mm})$; and $H, h, B$, and $b$ are the maximum outer diameter, minimum outer diameter, maximum inner diameter, and minimum inner diameter of the fracture section, respectively.

\section{MICRO-CT SCANNING}

To determine the BMD and microarchitecture, the right femur was scanned using a micro-CT scanner (GE eXplore Locus SP Micro-CT, GE Healthcare, Barrington, IL, USA). All scans were performed with $80 \mathrm{kV}$ tube voltage and $80 \mu \mathrm{A}$ tube current and an exposure time of $3000 \mathrm{~ms}$. The voxel size was $8.0 \mu \mathrm{m} \times 8.0 \mu \mathrm{m} \times$ $8.0 \mu \mathrm{m}$ for the trabecule analysis, and the angle of the increment was set to $0.5^{\circ}$. A fixed threshold was used to extract the mineralized bone phase by averaging the critical value of the grayscale. The region of interest (ROI) was the entire volume inside the femur head. The trabecular volumetric BMD (vBMD), representing the apparent $\mathrm{BMD}$ of the trabecule at the organ level, was calculated from all voxels in the ROI. The trabecular tissue BMD (tBMD), representing the BMD at the tissue level, was defined as the tissue mineral content divided by the volume of the fixed threshold voxels.

Other data were also calculated from the ROI, including bone volume fraction (BV/TV), trabecular number (Tb.N), trabecular thickness (Tb.Th), and trabecular separation (Tb.Sp). For the cortical bone, the data were taken from a 2-mm-long round region of the mid-diaphysis femur and included the mean thickness (Ct.Th), bone mineral content (BMC) and density (BMD), total area (Tt.Ar), cortical area (Ct.Ar), marrow area (Ma.Ar), and cortical area fraction (Ct.Ar/Tt.Ar) (Bouxsein et al., 2010).

All the micro-CT data were calculated using MicroView v2.1.1 software and Advanced Bone Analysis application (GE Healthcare, Barrington, IL, USA).

\section{BIOCHEMICAL ASSAYS OF SERUM MARKERS}

The blood samples were allowed to clot undisturbed for $30 \mathrm{~min}$ at room temperature. The sera were separated from the blood samples by centrifugation at $1,500 \mathrm{rpm}$ for $15 \mathrm{~min}$. The serum total cholesterol $(\mathrm{mmol} / \mathrm{L})$, triglycerides $(\mathrm{mmol} / \mathrm{L})$, alkaline phosphatase $(\mathrm{ALP}, \mathrm{IU} / \mathrm{L})$, calcium $\left(\mathrm{Ca}^{2+}, \mathrm{mmol} / \mathrm{L}\right)$, and phosphorus $(\mathrm{P}, \mathrm{mmol} / \mathrm{L})$ were measured using an automated HITACHI 7600 clinical analyzer (HITACHI, Ltd., Tokyo, Japan).

The serum estradiol levels were measured using a mouse estradiol (E2) ELISA Assay Kit according to the manual (Nanjing Jiancheng Bioengineering Institute, Nanjing, China). Briefly, $40 \mu \mathrm{l}$ samples, $10 \mu \mathrm{l}$ biotin-labeled mouse E2 antibodies, and $50 \mu \mathrm{l}$ HRP-conjugated streptavidin were combined in this order in the assay plate wells, which were pre-coated with mouse E2 monoclonal antibody. After incubation for $60 \mathrm{~min}$ at $37^{\circ} \mathrm{C}$, the plate was washed five times to remove the uncombined enzyme, and the substrate components A $(50 \mu \mathrm{l})$ and $\mathrm{B}(50 \mu \mathrm{l})$ were added to the well. After approximately $15 \mathrm{~min}$ of reaction time, the reaction was stopped by adding $50 \mu \mathrm{l}$ of the stop solution. The OD at $450 \mathrm{~nm}$ was measured using a FlexStation 3 microplate reader.

The serum leptin levels were measured using a mouse leptin ELISA kit (Crystal Chem, Downers Grove, IL, USA) according to the manufacturer's instructions. Briefly, $45 \mu \mathrm{l}$ of the sample diluent, $50 \mu \mathrm{l}$ anti-mouse leptin serum, and $5 \mu \mathrm{l}$ sample were added in this order to the assay plate wells, which were pre-coated with mouse leptin antibody. After incubation overnight at $4^{\circ} \mathrm{C}$, the plate was washed five times to remove the uncombined enzyme, and $100 \mu \mathrm{l}$ substrate was added to each well. After approximately $30 \mathrm{~min}$ at room temperature, the reaction was stopped by adding 
$100 \mu \mathrm{l}$ stop solution. The ODs at 450 and $630 \mathrm{~nm}$ were measured using a FlexStation 3 microplate reader.

\section{STATISTICAL ANALYSIS}

Ten C57BL/6 mice, 12 APP/PS1 mice, and 11 APP/PS1 + HFD mice were fed since 3 months old. Thus, for the measurements of body weight, spatial learning and memory, and mechanical properties, the sample size was 10 for C57BL/6 mice, 12 for APP/PS1 mice, and 11 for APP/PS1 + HFD mice. When the mice were sacrificed, 3 mice from each group were randomly selected to perfuse paraformaldehyde for immunohistochemistry experiments (data not shown in the text). For ELISA and western blot, the sample size is 7 for C57BL/6 mice, 9 for APP/PS1 mice, and eight for APP/PS1 + HFD mice. Due to the fact that a femur in APP/PS1 group was damaged and excluded from samples, 7 of C57BL/6 mice, 8 of APP/PS1 mice, and 8 of APP/PS1 + HFD mice were used for the micro-CT scanning.

All data were expressed as the means \pm SEM. One-way analysis of variance (ANOVA) with a Newman-Keuls post hoc test or two-way ANOVA with a Bonferroni's post hoc test was used to determine the differences among the groups. Significance was defined at the 0.05 level.

\section{RESULTS}

\section{BODY WEIGHT, PERIMETRIC FAT WEIGHT, AND LEVELS OF SERUM CHOLESTEROL AND TRIGLYCERIDE}

During the feeding period, the initial body weights of the mice were $21.66 \pm 1.29 \mathrm{~g}$, and the final body weights of APP/PS1 + HFD mice $(46.00 \pm 9.72 \mathrm{~g})$ were approximately 77.2 and $68.8 \%$ greater than those of $\mathrm{C} 57 \mathrm{BL} / 6(25.96 \pm 1.29 \mathrm{~g})$ and APP/PS1 mice $(27.25 \pm 1.45 \mathrm{~g})$, respectively, whereas no difference was found between the body weights of the C57BL/6 mice and APP/PS1 groups (Figure 1A). The ratio of the perimetric fat pad weight to body weight was 1.7 and 1.0 times higher in the APP/PS1 + HFD mice than those of the C57BL/6 and APP/PS1 mice, respectively (Figure 1B). A higher level of serum cholesterol was observed in the transgenic mice that were fed the HFD, while levels of serum triglycerides were not different among all groups (Figures 1C,D).

\section{EXPLORATION ABILITY AND SPATIAL LEARNING AND MEMORY MEASURED BY T-MAZE AND WATER MAZE}

To evaluate whether the HFD accelerated the development of $\mathrm{AD}$, the behavioral tests ( $\mathrm{T}$-maze and water maze) were conducted in the 9-month-old animals. The APP/PS1 group and APP/PS1 + HFD group exhibited impaired exploration ability, spatial learning and memory abilities, as indicated by fewer alternative choices and longer latency in the T-maze test, and longer escape latency and distance during training phase, and fewer crossings on the platform during probe trial in the water maze test compared to the C57BL/6 mice. Notably, no significant behavioral differences were found between the APP/PS1 and APP/PS1 + HFD groups (Figures 2A-E) in this study, suggesting that feeding a diet at a level of $45 \%$ calorie from fat for as long as 6 months does not lead to a detriment of exploration ability, spatial learning and memory in the female transgenic mouse model of $\mathrm{AD}$.
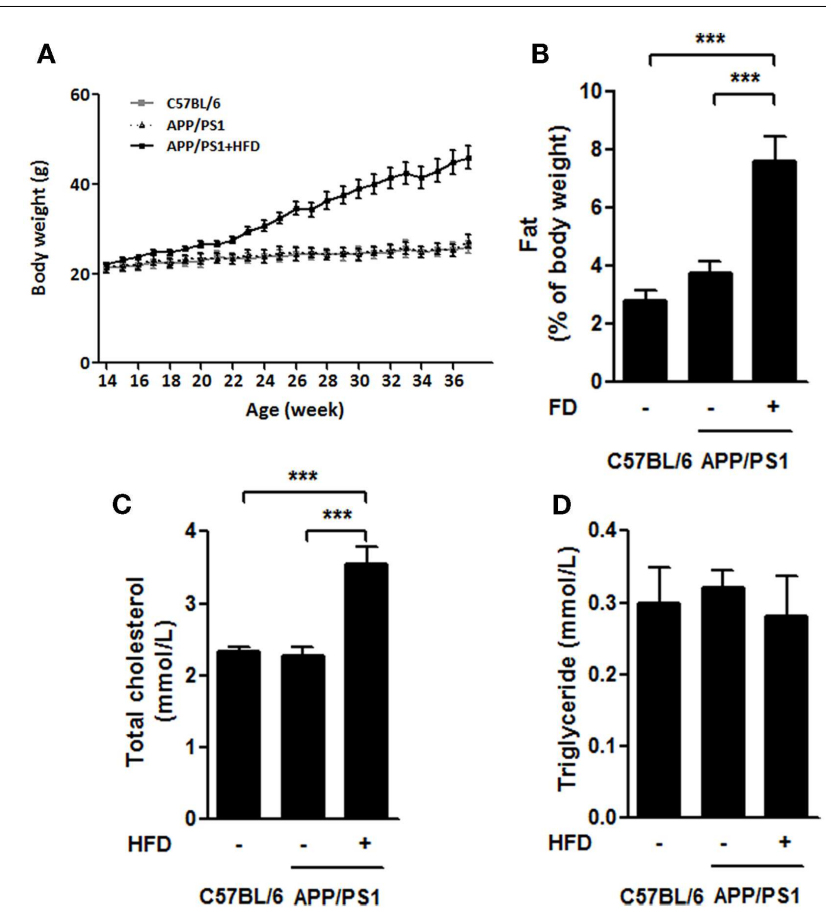

FIGURE 1 | High-fat-diet-induced weight gain in APP/PS1 mice. Throughout the experiment, the body weights of C57BL/6 and APP/PS1 mice had no difference, and significant body weight gain was induced after HFD feeding for 8 weeks (at 22 weeks) and sustained growing from then on (A). The ratio of parametric fat pad weight to body weight (B) of APP/ PS1 + HFD mice was significantly higher than that of the C57BL/6 and APP/PS1 mice. The serum level of total cholesterol in APP/PS1 + HFD mice was higher than those in the other two mice groups (C). No difference in serum triglycerides was found among the three groups (D). Data were means \pm SEM. $n=10$ for C57BL/6 mice, $n=12$ for APP/PS1 mice, and $n=11$ for APP/PS1 + HFD mice for body weight. $n=7$ for C57BL/6 mice, $n=9$ for APP/PS1 mice, and $n=8$ for APP/PS1 + HFD mice for other measurements. All results were analyzed by one-way ANOVA, followed by Newman-Keuls post hoc test, except that the body weight result was analyzed by two-way ANOVA, followed by Bonferroni's post hoc test. ${ }^{* * *} p<0.001$.

\section{BRAIN INSULIN SIGNALING AND A $\beta$ PP PROCESSING}

Neuronal insulin resistance has been confirmed in the brain of AD (Talbot et al., 2012). The neuronal insulin acts through a similar tyrosine kinase pathway as peripheral insulin acts. Insulin binds to insulin receptor (IR) followed by phosphorylation of phosphatidylinositol 3-kinase (PI3K), which leads to AKT/protein kinase $\mathrm{B}(\mathrm{PKB})$ phosphorylation and activation, and then glycogen synthesis kinase 3 (GSK3) is phosphorylated and inactivated (El Khoury et al., 2014). HFD feeding is linked to cognitive impairment mediated by brain insulin resistance and accelerated $\mathrm{A} \beta$ generation (Ho et al., 2004; McNeilly et al., 2011). The neural levels of p-AKT and p-GSK3 were determined in this study to evaluate the brain insulin signaling. The $\mathrm{A} \beta$ levels were also measured in APP/PS1 mice fed HFD (Figures 3A-I).

In $C 57 \mathrm{BL} / 6$ mice, soluble $A \beta_{40}$ and $A \beta_{42}$ levels measured by ELISA, and $A \beta$ precursor protein (A $\beta P P), A \beta$ tetramer, and $A \beta$ dimer levels assessed by western blots turned out to be very low or zero, whereas APP/PS1 and APP/PS1 + HFD mice had much 


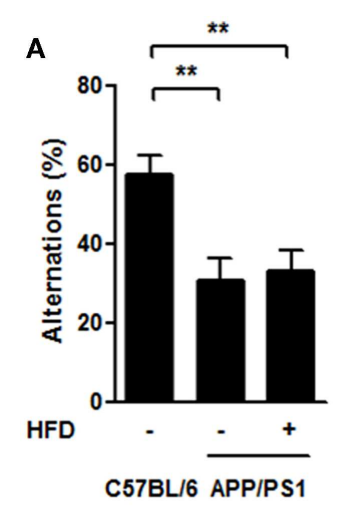

C

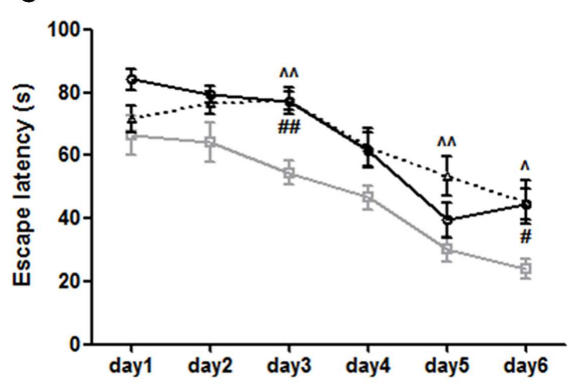

FIGURE 2 | HFD did not deteriorate the working, learning and memory performance in APP/PS1 mice. In the T-maze spontaneous alternation test, both APP/PS1 group and APP/PS1 + HFD group showed fewer percentages to make the alternative choices (A) and had a longer latency time (B) than C57BL/6 group. APP/PS1 group exhibited significant longer escape latency on days 3,5, and 6, and longer distance on days 2 , 3 , 4, and 5, while APP/PS1 + HFD group exhibited significant longer escape latency on days 3 , and 6 , and longer distance on days 2 and 3 (C,D). The mean crossings of the C57BL/6 group were more frequent than

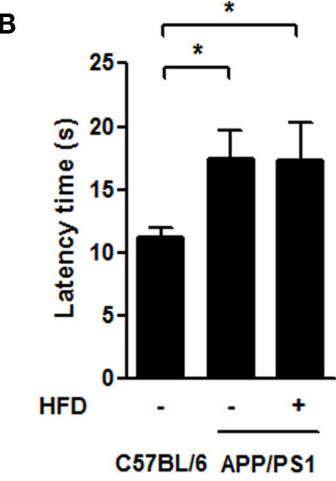

E

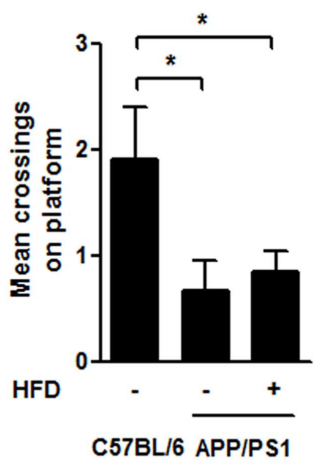

D

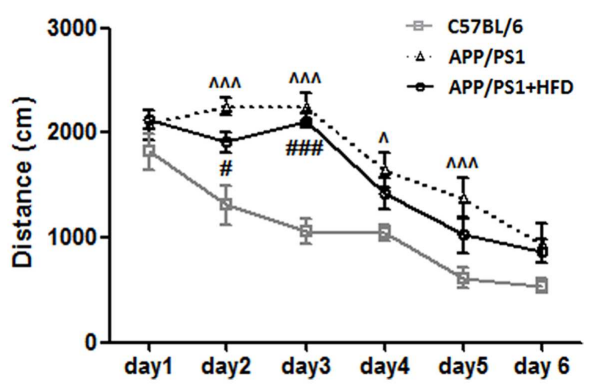

those of APP/PS1 and APP/PS1 + HFD groups (E). Additionally, no difference was found between the APP/PS1 and APP/PS1 + HFD groups. Data were means \pm SEM. $n=10$ for C57BL/6 mice, $n=12$ for APP/PS1 mice, and $n=11$ for APP/PS1 + HFD mice. T-maze results were analyzed by one-way ANOVA, followed by Newman-Keuls post hoc test. ${ }^{*} p<0.05$; ${ }^{* *} p<0.01$. The water maze result was analyzed by two-way ANOVA, followed by Bonferroni's post hoc test. ${ }^{\wedge} p<0.05 ;{ }^{\wedge} p<0.01$; ${ }^{\wedge \wedge} p<0.001$, APP/PS1 versus C57BL/6; ${ }^{\prime} p<0.05 ; " \# p<0.01 ; \# p<0.001$, APP/PS1 + $\mathrm{HFD}$ versus $\mathrm{C} 57 \mathrm{BL} / 6$. higher levels of those parameters (Figures 3A-F). Importantly, the $A \beta_{40}, A \beta_{42}, A \beta P P, A \beta$ tetramer, and $A \beta$ dimer levels were comparable in the APP/PS1 + HFD mice and the APP/PS1 mice fed the normal-fat diet (Figures 3A-F). Consistent with these observations, the APP/PS1 and APP/PS1 + HFD mice showed elevated levels of AKT phosphorylation compared to the C57BL/6 mice, but no significant differences between APP/PS1 and APP/PS1 + HFD mice were observed (Figures 3G,H). The p-GSK3 $\beta$ expression was even higher in APP/PS1 + HFD mice than in APP/PS1 and C57BL/6 mice (Figures 3G,I). These results suggested that HFD did not aggravate $A \beta$ generation and brain insulin signaling impairment in the female transgenic mice.

\section{MECHANICAL PARAMETERS OF THE FEMORAL BONE}

To understand the mechanical effects of AD pathology and HFDinduced body weight gain on bone, we employed the three-point bending test to measure the mechanical properties of the femurs (Figures 4A-H). We found that the elastic force and ultimate force were both significantly reduced in APP/PS1 mice compared to the age-matched $\mathrm{C} 57 \mathrm{BL} / 6$ mice and that these effects were completely reversed by the HFD (Figures $4 \mathbf{A}, \mathbf{B}$ ). With respect to the second moment of inertia, which reflects the geometric size of bone, and load-displacement curve, we found that elastic stress and energy absorption decreased in the APP/PS1 mice and were reversed by the HFD (Figures 4C-E). Although no differences in the elastic modulus and stiffness were observed between the C57BL/6 and APP/PS1 mice, HFD significantly increased the values of these two parameters (Figures 4F,G). Ultimate stress was not different among the three groups of mice (Figure $4 \mathbf{H}$ ). The femur length was shorter in APP/PS1 mice compared to C57BL/6 mice, and this effect was not altered by the HFD (Figure 4I).

\section{BONE MINERAL DENSITY AND MICROARCHITECTURAL PARAMETERS OF THE FEMORAL BONE}

To determine the structural basis for the alteration in biomechanical properties, we further evaluated the cortical bone in femurs using a micro-CT system. Compared to the C57BL/6 group, the $\mathrm{APP} / \mathrm{PS} 1$ group had lower values for BMD, BMC, and mean thickness (Ct.Th) of cortical femur but showed no significant decreases in total area (Tt.Ar) and cortical area (Ct.Ar) (Figures 5A-E,H). Ct.Ar/Tt.Ar was decreased in the APP/PS1 mice (Figure 5G) compared with the C57BL/6 mice. HFD feeding resulted in significant increases in BMD, BMC, Ct.Th, Tt.Ar, and Ct.Ar of the measured bone in APP/PS1 mice (Figures 5A-E,H). There were no significant differences in marrow area (Ma.Ar) among the groups (Figure 5F). The micrographs also revealed that the inner bone 

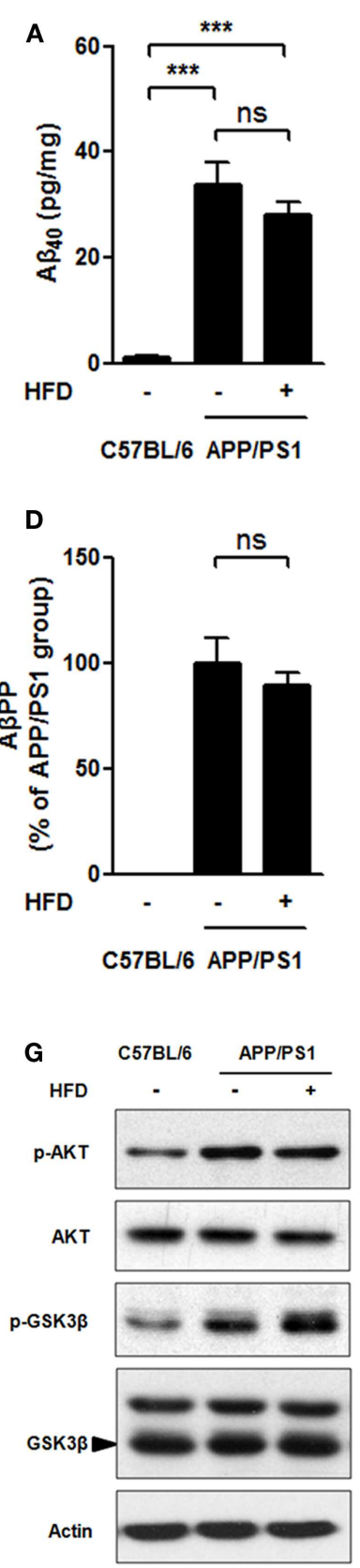
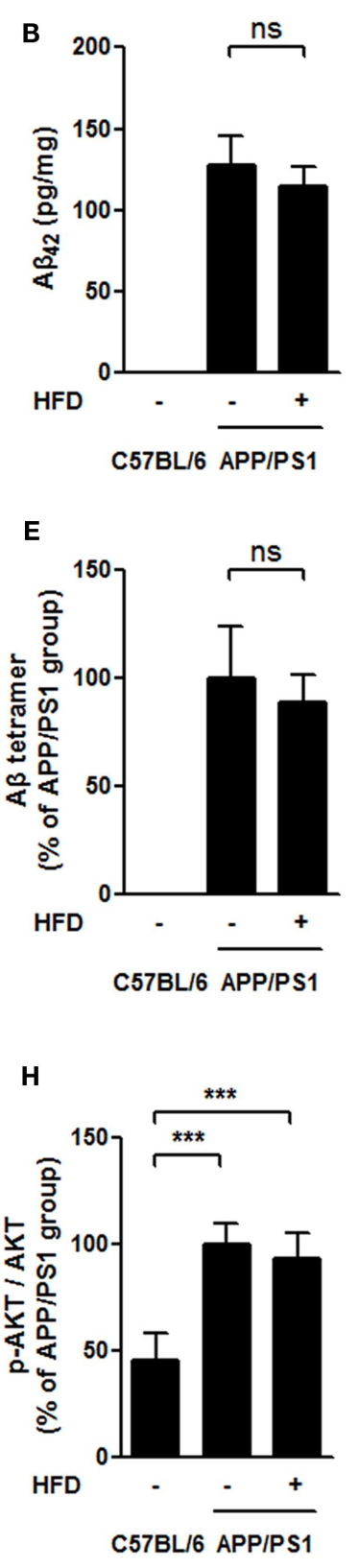

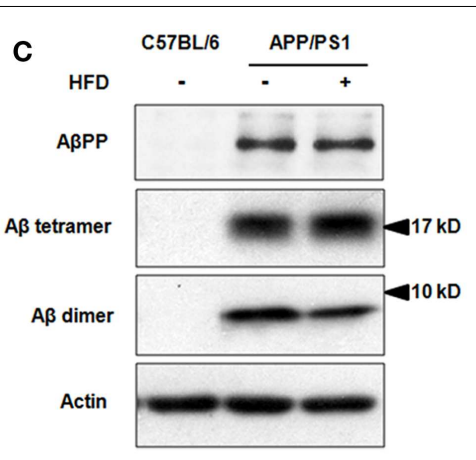

$\mathbf{F}$
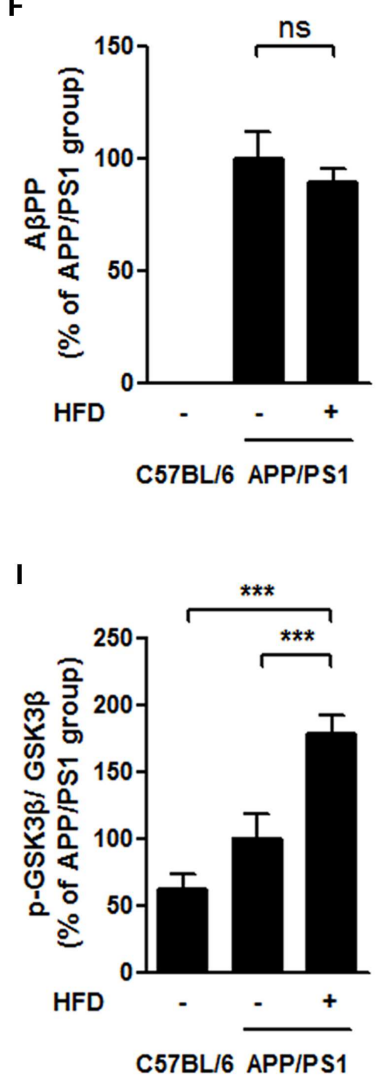

FIGURE 3 | Soluble $\mathbf{A} \boldsymbol{\beta}$ level and brain insulin signaling. $A \beta_{40}(\mathbf{A})$, and $A \beta_{42}$ (B) levels were much higher in APP/PS1 and APP/PS1 + HFD mice compared with that those of $C 57 \mathrm{BL} / 6$ mice, and the $A \beta_{40}$ and $A \beta_{42}$ levels were determined to be the same between APP/PS1 and APP/PS1 + HFD mice by ELISA. The expression of A $\beta P P, A \beta$ tetramer, $A \beta$ dimer (C), phosphorylation of AKT, and phosphorylation of GSK3 $\beta(\mathbf{G})$ in brain tissue were analyzed by western blot. Quantification of western blot of A $\beta P P(\mathbf{D}), A \beta$ tetramer (E), A $\beta$ dimer (F), p-AKT (H), and p-GSK3 $\beta$ (I). Data were means \pm SEM. $n=7$ for C57BL/6 mice, $n=9$ for APP/PS1 mice, and $n=8$ for APP/PS1 + HFD mice. The results were analyzed by one-way ANOVA, followed by Newman-Keuls post hoc test. *** $p<0.001$. surface facing the marrow was much smoother in the C57BL/6 and APP/PS1 + HFD groups than in APP/PS1 group (Figure $\mathbf{5 H}$ ).

The femoral trabecular bone mass was also evaluated by microCT (Figures 6A-H). We found that the vBMD, tBMD, and trabecular thickness (Tb.Th) were the same in APP/PS1 mice and $\mathrm{C} 57 \mathrm{BL} / 6$ mice, but these parameters were all significantly increased by the HFD feeding (Figures 6A,B,F,H). The trabecular separation (Tb.Sp) was similar in the APP/PS1 mice compared with the C57BL/6 mice but was reduced in mice on the HFD (Figure 6G). No significant differences in the BMC and trabecular number (Tb.N) were found among all groups (Figures 6C,E). The bone volume fraction (BV/TV) was lower in APP/PS1 mice than in the C57BL/6 mice and was corrected by the HFD feeding (Figure 6D). 

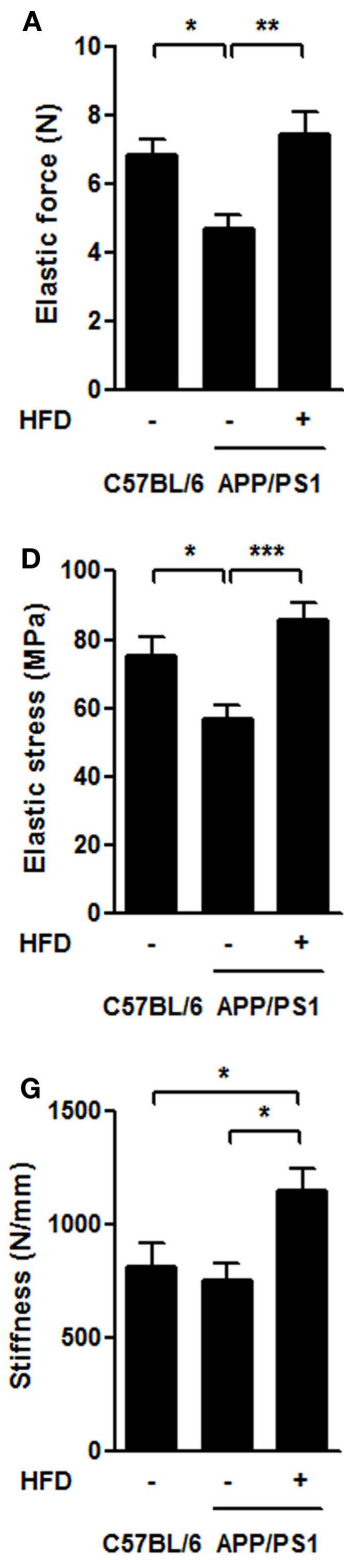
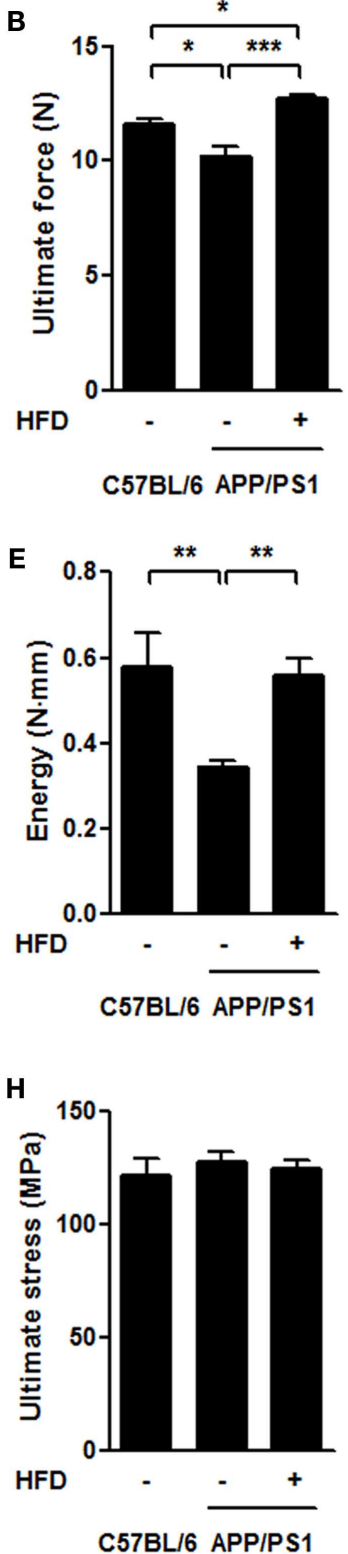

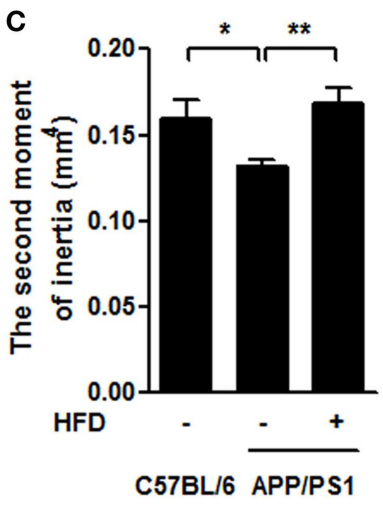

$\mathbf{F}$

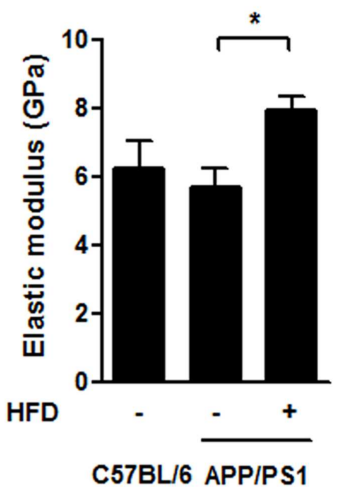

I

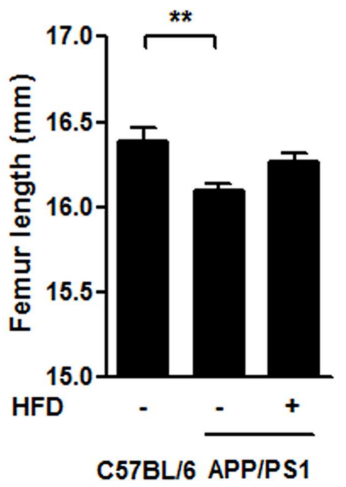

FIGURE 4 | HFD ameliorated impairments of femoral mechanical properties in APP/PS1 mice. In the three-point bending test, the elastic force (A), ultimate force (B), second moment of inertia (C), elastic stress (D), and energy (E) were all significantly reduced in APP/PS1 mice compared to the age-matched C57BL/6 mice. No difference was found in elastic modulus (F) and stiffness (G) between C57BL/6 and APP/PS1 mice, but HFD significantly increased these two parameters. Ultimate stress did not vary among the three groups $\mathbf{( H )}$. Femur length was shorter in APP/PS1 mice but not reversed by HFD (I). Data were means \pm SEM. $n=10$ for C57BL/6 mice, $n=12$ for APP/PS1 mice, and $n=11$ for APP/PS1 + HFD mice. The results were analyzed by one-way ANOVA, followed by Newman-Keuls post hoc test. ${ }^{*} p<0.05 ;{ }^{*} p<0.01 ;{ }^{* *} p<0.001$.

\section{SERUM ALKALINE PHOSPHATASE, CALCIUM, PHOSPHORUS, \\ ESTROGEN AND LEPTIN LEVELS}

Several bone-remodeling-related markers, including serum ALP, calcium $\left(\mathrm{Ca}^{2+}\right)$, phosphorus $(\mathrm{P})$, circulating leptin and estradiol (Figures 7A-E), were measured in this study. The ALP activity was much higher in the APP/PS1 mice than in the C57BL/6 mice and this increase was significantly reversed by HFD feeding (Figure 7A). We found no significant difference in $\mathrm{Ca}^{2+}$ levels either between APP/PS1 mice and C57BL/6 mice, or between $\mathrm{APP} / \mathrm{PS} 1$ mice and APP/PS1 + HFD mice, but $\mathrm{Ca}^{2+}$ levels were elevated in the APP/PS1 + HFD group compared with that in the $\mathrm{C} 57 \mathrm{BL} / 6$ group (Figure $7 \mathrm{~B}$ ). The $\mathrm{P}$ concentration was higher in the APP/PS1 mice than in the C57BL/6 group, but this effect was unchanged by HFD feeding (Figure 7C). We found a lower concentration of estrogen in the APP/PS1 mice relative to the C57BL/6 mice, and the low level remained in the HFD-fed mice (Figure 7D). In contrast, there was a trend toward decreased levels of leptin in the APP/PS1 mice $(p=0.07)$ compared with the C57BL/6 mice, and this parameter was significantly elevated by the HFD feeding (Figure 7E). 

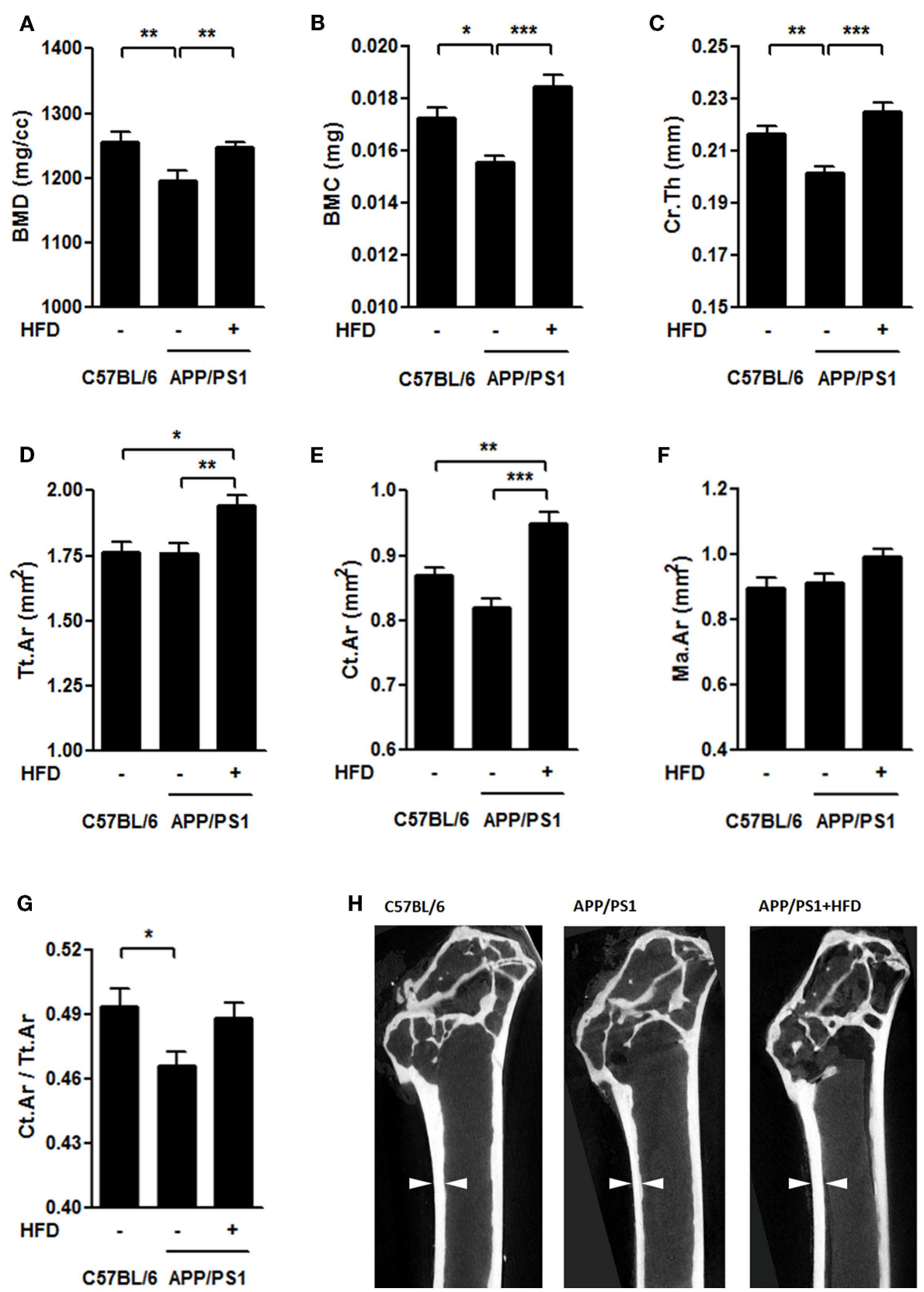

FIGURE 5 | HFD protected femoral cortical bone from AD-involved impairments. The bone mineral density [BMD, (A)], bone mineral content [BMC, (B)], and mean thickness [Cr.Th (C)] were lower in the APP/PS1 mice compared to the C57BL/6 mice, all of which were reversed by HFD feeding No significant decrease was found in total area [Tt.Ar (D)] and cortical area [Ct.Ar (E)] in the APP/PS1 mice compared to the C57BL/6 mice, whereas, both of which were elevated by HFD feeding. Marrow area (Ma.Ar) did not vary among the three groups (F). The ratio of Ct.Ar to Tt.Ar was decreased in APP/PS1 mice (G), but not reversed by HFD feeding. Micrographs showed the differences of thickness and inner bone surface among all the groups with arrows indicating the representative part $\mathbf{( H )}$. Data were means \pm SEM. $n=7$ for C57BL/6 mice, $n=8$ for APP/PS1 mice, and $n=8$ for APP/PS1 + HFD mice. The results were analyzed by one-way ANOVA, followed by Newman-Keuls post hoc test. ${ }^{*} p<0.05 ;{ }^{* *} p<0.01 ;{ }^{*}{ }^{*} p<0.001$

\section{DISCUSSION}

SEVERE BONE LOSS AND IMPAIRED BIOMECHANICAL PROPERTIES OF THE FEMUR IN FEMALE APP/PS1 TRANSGENIC MICE

In APP/PS1 mice, the amyloid pathology can be observed in mice as young as 3 months, and the amyloid plaque is widely spread by middle age ( 9 to 12 months old) (Garcia-Alloza et al., 2006).
In an earlier study by Yang et al., the measurement of BMD and microarchitecture parameters of both C57BL/6 mice and APP/PS1 mice was performed at the age of 6,9 , and 12 months, respectively. They found that, even though the amyloid pathology occurred as early as 3-month age in APP/PS1 mice, the deviation of BMD and microarchitecture could not be found until 9 months old. And 


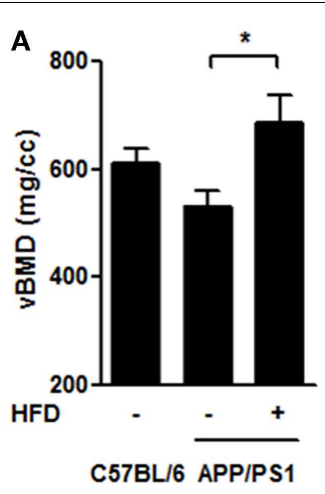

D

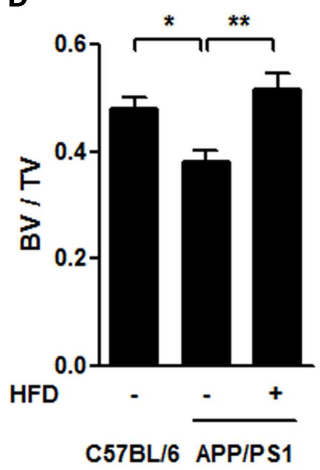

G

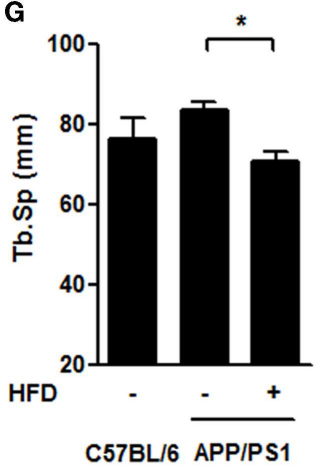



E

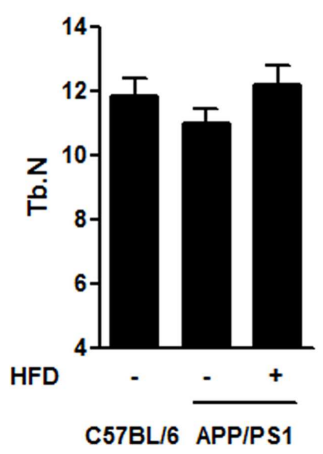

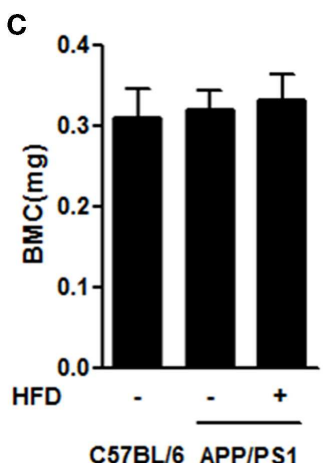

$\mathbf{F}$

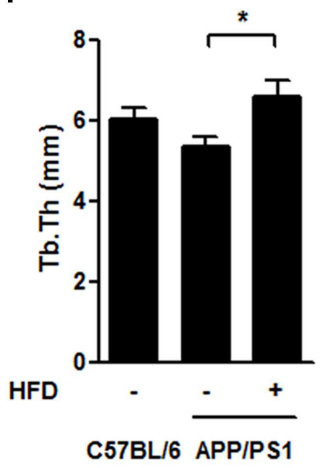

H

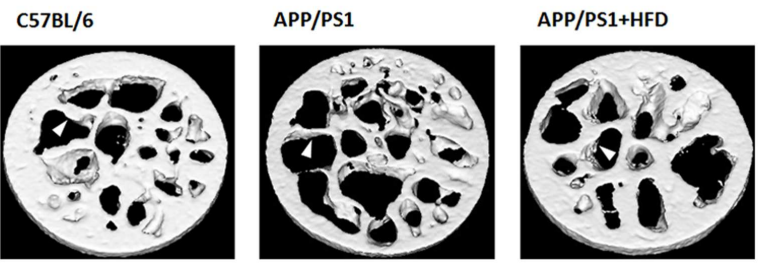

FIGURE 6 | HFD improved microarchitecture of femur trabecular bone in APP/PS1 mice. The volumetric BMD [vBMD (A)], tissue BMD [tBMD (B)], and trabecular thickness [Tb.Th (F)] were not significantly altered in C57BL/6 mice and APP/PS1 mice; however, these parameters significantly increased after HFD. Bone volume fraction [BV/TV (D)] was lower in APP/PS1 mice and recovered after HFD feeding. No significant differences in BMC (C) or trabecular number [Tb. N (E)] were found among the three groups. The trabecular separation [Tb.Sp (G)] was not significantly altered in C57BL/6 mice or APP/PS1 mice, and it was reduced after HFD. Micrographs showed the microarchitecture of femoral trabecule $\mathbf{( H )}$ with arrows indicating the representative part. Data were means \pm SEM. $n=7$ for C57BL/6 mice, $n=8$ for APP/PS1 mice, and $n=8$ for APP/PS1 + HFD mice. The results were analyzed by one-way ANOVA, followed by Newman-Keuls post hoc test. ${ }^{*} p<0.05 ;{ }^{*} p<0.01$. at a later time point (12-month age), the deviation of BMD and microarchitecture become more obvious between AD and control mice. Therefore, taking the factors into consideration - amyloid pathology (as early as 3-month old) and osteoporosis pathology (at 9-month old), we evaluated the bone remodeling induced by weight gain during the period from $\mathrm{AD}$ pathogenesis to the typical pathology development, i.e., AD mice were given an HFD at 3 months of age and this lasted for 6 months, and the mice were then sacrificed at 9 months for all the measurements. By measuring the bone mechanical properties with the three-point bending test and measuring the BMD and microarchitecture with the micro-CT system, severe bone loss was detected in the femoral cortical bone of the transgenic mouse model of $\mathrm{AD}$, suggesting that bone loss may be associated with amyloid pathogenesis (Yang et al., 2011; Xia et al., 2013).

As a result of the bone loss, the biomechanical properties of the femur were severely impaired in the $\mathrm{AD}$ mice compared with the age-matched C57BL/6 mice (Figure 4). These bone 

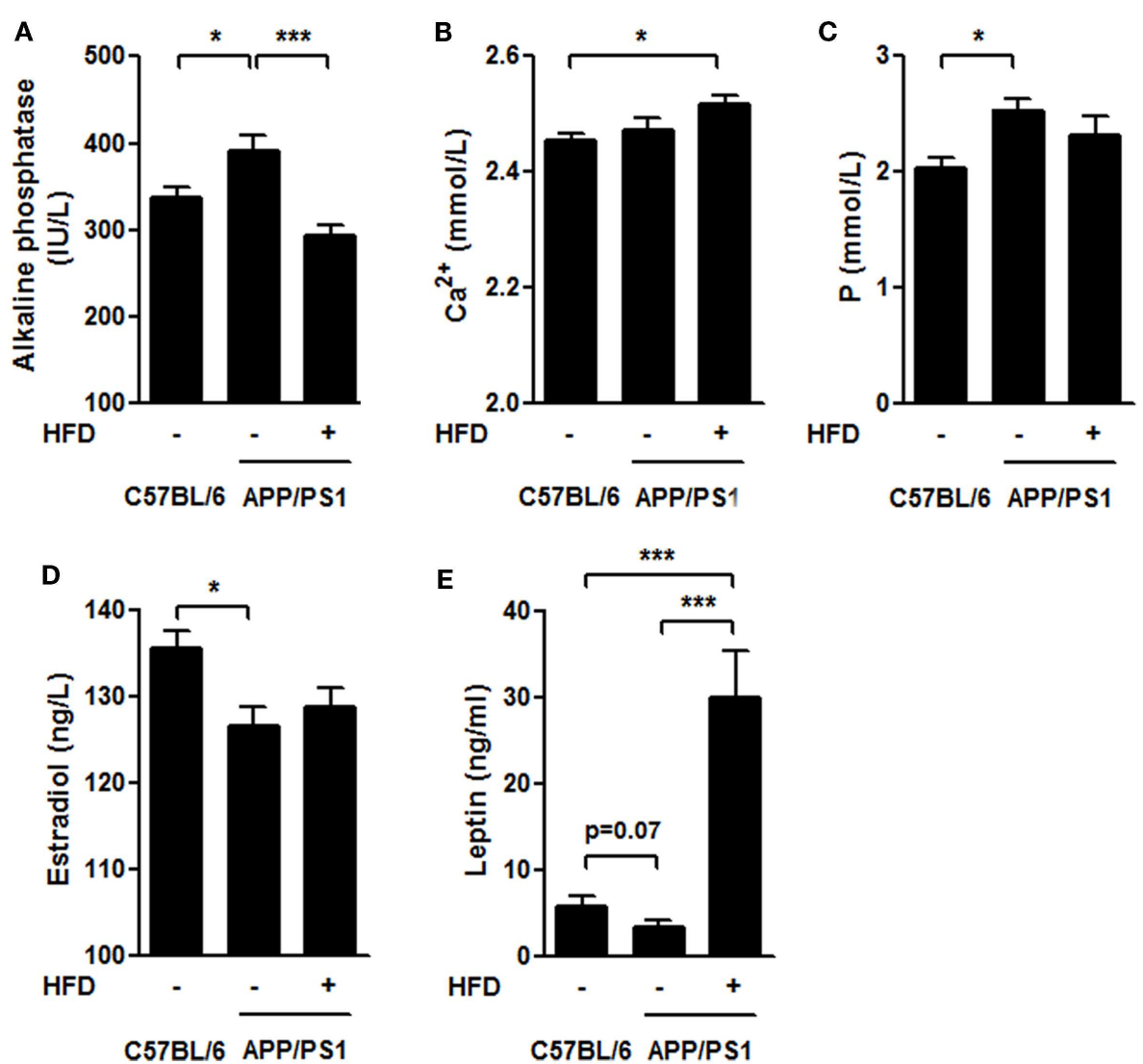

FIGURE 7 | Serum biochemical characteristics. The ALP level was higher in APP/PS1 mice than that in C57BL/6 mice, and it was reversed after HFD feeding (A). The serum $\mathrm{Ca}^{2+}$ levels in APP/PS1 mice was not different from that of C57BL/6 or APP/PS1 + HFD mice; however, it was higher in APP/PS1 + HFD mice than that in C57BL/6 mice (B). The serum phosphorus level was higher in APP/PS1 mice than that in C57BL/6 mice, which was not reversed by HFD feeding (C). APP/PS1 mice had a lower estrogen level than C57BL/6 mice, which was also not reversed by HFD feeding (D). The serum leptin level was lower in APP/PS1 mice compared to $\mathrm{C} 57 \mathrm{BL} / 6$ mice $(p=0.07$ ), and it was significantly induced after HFD feeding (E). Data were means \pm SEM. $n=7$ for C57BL/6 mice, $n=9$ for APP/PS1 mice, and $n=8$ for APP/PS1 + HFD mice. The results were analyzed by one-way ANOVA, followed by Newman-Keuls post hoc test. ${ }^{*} p<0.05 ;{ }^{* *} p<0.001$. impairments were consistent with the serum biochemical indexes, including elevated serum ALP levels and P levels in the transgenic mice compared with the C57BL/6 mice (Figure 7). The results suggest a strong link between $\mathrm{AD}$ pathology and femoral bone impairment. In addition, we did not find the weight loss in middle-aged female $\mathrm{AD}$ mice in this study, because it is supposed to emerge in the later stage of the $\mathrm{AD}$ with more severe bone loss.

Yang et al. (2011) reported that in 9-month-old APP/PS1 mice, parameters including vBMD, tBMD, BV/TV, Tb.Th, and Tb.Sp in the proximal metaphysis of the tibiae differed from those in C57BL/6 mice. In this study, the femoral trabecule of the APP/PS1 mice showed no significant alternations of these parameters compared with the control mice (Figure 6). The differences of bone mass between tibiae and femoral trabecule in APP/PS1 mice may be due to the presence of fewer trabecule in the femur than that in the tibia. This finding is consistent with the observation that the femur is more resistant to bone loss than tibia (Lelovas et al., 2008).

\section{MODERATE WEIGHT GAIN INDUCED BY HFD BENEFITS AD-INVOLVED BONE LOSS WITH NO DETRIMENTS OF EXPLORATION ABILITY AND SPATIAL LEARNING AND MEMORY}

In patients with $\mathrm{AD}$, weight loss and osteoporosis are observed and become worse with AD progression (White et al., 1996; CroninStubbs et al., 1997; Tan et al., 2005; Lelovas et al., 2008; Zhou et al., 2011), and the relative risk of death is positively correlated with increased weight loss in AD cases (White et al., 1998). In contrast to the weight loss, extreme obesity is a definite risk factor for many diseases, such as cardiovascular disease and cancer. A new metaanalysis revealed that obese people, particularly those who are extremely obese, tend to die earlier than those of normal weight. However, the findings also suggest that people who are overweight (but not obese) may live longer than people with clinically normal body weight (Flegal et al., 2013; Couzin-Frankel, 2014; Solon-Biet et al., 2014). A lot of studies reported that osteoporosis is accompanied with weight loss and bone mass can be improved by weight gain (Felson et al., 1993; Tremollieres et al., 1993; Frederich et al., 1995; Considine et al., 1996; Ravn et al., 1999; Lin et al., 2000; De 
Laet et al., 2005; Sheu and Cauley, 2011; Greco et al., 2013; Johansson et al., 2014). As expected in this study, the lower values of BMD and mechanical properties of the femur in transgenic mice were greatly improved by weight gain.

Notably, the benefit of HFD on bone health is specific for $\mathrm{AD}$ mice but not for normal C57 mice. In a previous study by Ionova-Martin et al. (2011), 15-week-old C57BL/6 mice received 16-week duration of HFD. Ultimate stress and ultimate force were $15 \%$ and $22 \%$ less in HFD-fed C57BL/6 mice compared with those in normal diet-fed C57BL/6 mice, respectively, while BMD, length, diameter, elastic modulus, and yield stress of their femora were comparable with those in normal diet-fed C57BL/6 mice. In another report by Shen et al. (2013), 3-month-old rats were given an 8-month duration of HFD. They found that HFD feeding increased bone formation and erosion rates, and decreased trabecular thickness at the tibia. BMD, Tb.N, and Tb.Th of femur in these HFD-fed rats were comparable with those in normal diet-fed rats. These studies clearly demonstrated that HFD feeding slightly influenced the mechanical properties and microarchitecture of bone in rodents.

The femoral bone benefits were fully demonstrated in this study; however, there is particular concern that body weight gain is generally linked to cognitive detriments. In this study, we avoided the extreme HFD (60\% calorie from fat) feeding, which is known to lead to severe obesity, brain insulin resistance, and spatial memory impairment both in $\mathrm{AD}$ mouse model and normal C57BL/6 mouse (Ho et al., 2004; Moroz et al., 2008; Barron et al., 2013; Leboucher et al., 2013). Instead, we employed a 6-month feeding regimen of a $45 \%$ fat diet which resulted in a body weight gain in the transgenic mouse model of AD. The 6-month HFD feeding was implemented in 3-month-old APP/PS1 mice. Body weight at 5,7 , and 9 months (the end of the feeding) of HFD-fed mice were $17.9,60.1$, and $68.8 \%$ higher than the age-matched APP/PS1 mice fed with the normal-fat diet, respectively. These levels of weight gain are equivalent to a range of overweight to moderate obesity, but not severe obesity in humans. 45\% HFD feeding, as reported in previous study, caused little impairment in the rodent central insulin signaling and spatial memory (Mielke et al., 2006; McNeilly et al., 2012) but a disability in performance of an operant bar-pressing task (Mielke et al., 2006; McNeilly et al., 2011). We confirmed that HFD did not exacerbate the exploration ability and working, learning, and memory performance during the 6 months of feeding compared to the transgenic mice fed a normal-fat diet (Figures 2A-D). Furthermore, the brain $A \beta$ processing and brain insulin signaling, which are considered to be involved in $A \beta$ plaque deposit and cognition dysfunction (Farooki, 2009), were not significantly altered by the HFD feeding (Figures 3A-I). Therefore, a strategy of moderate body weight gain, such as by the mean of moderate HFD regimen, should not be precluded, especially in case of diseases with progressive weight loss such as AD and $\mathrm{AD}$-involved osteoporosis.

In addition to the effects of diets at different fat levels ( 10 or $45 \%$ calorie from fat) on spatial working, learning, and memory measurement as in this study, future studies should evaluate whether longer periods of HFD feeding lead to disability in other aspects of cognitive performance, such as delayed matching and nonmatching to position task. Additionally, it remains to be defined whether the fat or the muscle gain is responsible for the bone improvement during HFD feeding. And other metabolic disorders will also need to be carefully assessed in future studies.

\section{ELEVATED CIRCULATING LEPTIN INDUCED BY WEIGHT GAIN WAS INVOLVED IN BONE REMODELING IN FEMALE APP/PS1 MOUSE FED HFD}

Both estrogen and leptin exhibit regulatory effects on bone formation and degradation. Leptin can ameliorate OVX-induced osteoporosis (Burguera et al., 2001). These effects may be due to peripheral stimulation of osteoblast proliferation and inhibition of osteoclastogenesis mediated by signaling through osteoprotegerin (OPG)/receptor-activator of NF-кB (RANK) and its ligand (RANKL). However, an indirect action of leptin via estradiol cannot be excluded (Yasuda et al., 1998; Thomas et al., 1999; Burguera et al., 2001; Holloway et al., 2002; Martin and Sims, 2005; Wada et al., 2006; Xue et al., 2012).

In the APP/PS1 mice, we found that the serum estradiol levels were reduced compared with the C57BL/6 mice. HFD feeding did not alter the circulating level of estradiol in the transgenic mice (Figure 7D), implying that estrogen level may contribute to bone loss but is not associated with the body weight gain-induced improvement of the bone mass in the transgenic mice. This finding is consistent with a report that total estrogen was similar in both obese and non-obese postmenopausal women (Albala et al., 1996).

Previous reports have well addressed the role of leptin in the regulation of bone health showing that the administration of leptin leads to an increase in the BMD in mice (Burguera et al., 2001; Sienkiewicz et al., 2011). In the AD brain, there are higher levels of leptin but lower levels of leptin receptor mRNA, thus suggesting that the $\mathrm{AD}$ brain exhibits impaired brain leptin signaling, namely less leptin receptor, as well as less interaction between the leptin and leptin receptors (Lieb et al., 2009; Zhou et al., 2011; Bonda et al., 2013). The enhanced bone mass induced by weight gain in female APP/PS1 mice might therefore be attributed to the peripheral action of leptin rather than brain leptin signaling (Burguera et al., 2001), through peripheral stimulation of osteoblast proliferation and inhibition of osteoclastogenesis (Holloway et al., 2002; Martin and Sims, 2005). In contrast to the HFD-induced beneficial effect to the bone quality in $\mathrm{AD}$ mice, a higher level of leptin induced by HFD in adult C57BL/6 mice did not lead to enhanced bone mechanical properties (Ionova-Martin et al., 2011), which suggests that leptin acts differently in osteoporosis-involved $\mathrm{AD}$ mice than it does in normal controls fed with HFD. Here, in this study, we still lack solid evidence linking leptin to bone quality in $\mathrm{AD}$ mice. Therefore, the underlying mechanism of leptin in regulating osteoblast proliferation and osteoclastogenesis still needs to be elucidated in female patient with $\mathrm{AD}$.

Taken together, the body weight gain induced by the HFD feeding regimen completely improved the $\mathrm{AD}$-involved femoral bone loss without adverse effects on the exploration ability and spatial memory impairment in the APP/PS1 transgenic mouse model of $\mathrm{AD}$. Patients with $\mathrm{AD}$ always develop both progressive weight loss and osteoporosis. Our findings suggest that HFD may be an effective dietary administration for progressive weight loss and osteoporosis in patients with $\mathrm{AD}$ without a substantial impact on cognitive function. Further research is required to optimize the 
composition of the HFD in order to minimize the possible negative effect induced by HFD, for instance, the risk of cardiovascular disease and cognition impairment.

\section{AUTHOR CONTRIBUTIONS}

Yunhua Peng, Jing Liu, Jiangang Long, and Jiankang Liu contributed to the study conception and design. Yunhua Peng, Jing $\mathrm{Liu}, \mathrm{Hua} \mathrm{Li}$, Chen Hou, and Ying Tang performed the experiments and collected data. Yunhua Peng and Jing Liu performed data analysis. Data were interpreted by Yunhua Peng, Jing Liu, Jianshu Liu, Tingting Han, Jiangang Long, and Jiankang Liu. Yunhua Peng, Jiangang Long, and Jiankang Liu drafted the manuscript. All authors critically revised the content of the manuscript and approved its final version. Jiangang Long and Jiankang Liu take responsibility for the integrity of the data analysis.

\section{ACKNOWLEDGMENTS}

The study was supported by the opening foundation of the State Key Laboratory of Space Medicine Fundamentals and Application, China Astronaut Research and Training Center, grant No. SMFA10K07), the National Natural Science Foundation of China (Grant No. 30930105 and 31070740), New Century Excellent Talents in University, National "Twelfth Five-Year" Plan for Science and Technology Support, the Fundamental Research Funds for the Central Universities and Shaanxi province science and technology research and development program (2013K12-01-10). Finally, we thank Aileen Cheng for her help in language editing.

\section{SUPPLEMENTARY MATERIAL}

The Supplementary Material for this article can be found online at http://www.frontiersin.org/Journal/10.3389/fncel.2014.00225/ abstract

\section{REFERENCES}

Akhter, M., Wells, D., Short, S., Cullen, D., Johnson, M., Haynatzki, G., et al. (2004). Bone biomechanical properties in LRP5 mutant mice. Bone 35, 162-169. doi:10.1016/j.bone.2004.02.018

Albala, C., Yanez, M., Devoto, E., Sostin, C., Zeballos, L., and Santos, J. (1996). Obesity as a protective factor for postmenopausal osteoporosis. Int. J. Obes. Relat. Metab. Disord. 20, 1027-1032.

Alzheimer's Association. (2014). 2014 Alzheimer's disease facts and figures. Alzheimers Dement. 10, e47-e92. doi:10.1016/j.jalz.2014.02.001

Andersen, K., Launer, L. J., Dewey, M. E., Letenneur, L., Ott, A., Copeland, J. R., et al. (1999). Gender differences in the incidence of AD and vascular dementia: The EURODEM Studies. EURODEM Incidence Research Group. Neurology 53, 1992-1997. doi:10.1212/WNL.53.9.1992

Andersen, S., Frederiksen, K. D., Hansen, S., Brixen, K., Gram, J., and Støving, R. K. (2014). Bone structure and estimated bone strength in obese patients evaluated by high-resolution peripheral quantitative computed tomography. Calcif. Tissue Int. 95, 19-28. doi:10.1007/s00223-014-9857-4

Barron, A. M., Rosario, E. R., Elteriefi, R., and Pike, C. J. (2013). Sex-specific effects of high fat diet on indices of metabolic syndrome in 3xTg-AD mice: implications for Alzheimer's disease. PLoS ONE 8:e78554. doi:10.1371/journal.pone.0078554

Bonda, D. J., Stone, J. G., Torres, S. L., Siedlak, S. L., Perry, G., Kryscio, R., et al. (2013). Dysregulation of leptin signaling in Alzheimer disease: evidence for neuronal leptin resistance. J. Neurochem. 128, 162-172. doi:10.1111/jnc.12380

Bonnet, N., Bernard, P., Beaupied, H., Bizot, J., Trovero, F., Courteix, D., et al. (2007). Various effects of antidepressant drugs on bone microarchitecture, mechanical properties and bone remodeling. Toxicol. Appl. Pharmacol. 221, 111-118. doi:10.1016/j.taap.2007.02.005

Borchelt, D. R., Ratovitski, T., van Lare, J., Lee, M. K., Gonzales, V., Jenkins, N. A., et al. (1997). Accelerated amyloid deposition in the brains of transgenic mice coexpressing mutant presenilin 1 and amyloid precursor proteins. Neuron 19, 939-945. doi:10.1016/S0896-6273(00)80974-5

Bouxsein, M. L., Boyd, S. K., Christiansen, B. A., Guldberg, R. E., Jepsen, K. J., and Müller, R. (2010). Guidelines for assessment of bone microstructure in rodents using micro-computed tomography. J. Bone Miner. Res. 25, 1468-1486. doi:10.1002/jbmr.141

Bredesen, D. E., and John, V. (2013). Next generation therapeutics for Alzheimer's disease. EMBO Mol. Med. 5, 795-798. doi:10.1002/emmm.201202307

Burguera, B., Hofbauer, L. C., Thomas, T., Gori, F., Evans, G. L., Khosla, S., et al. (2001). Leptin reduces ovariectomy-induced bone loss in rats. Endocrinology 142, 3546-3553. doi:10.1210/endo.142.8.8346

Considine, R. V., Sinha, M. K., Heiman, M. L., Kriauciunas, A., Stephens, T. W., Nyce, M. R., et al. (1996). Serum immunoreactive-leptin concentrations in normal-weight and obese humans. N. Engl. J. Med. 334, 292-295. doi:10.1056/ NEJM199602013340503

Couzin-Frankel, J. (2014). Diet studies challenge thinking on proteins versus carbs. Science 343, 1068. doi:10.1126/science.343.6175.1068

Cronin-Stubbs, D., Beckett, L. A., Scherr, P. A., Field, T. S., Chown, M. J., Pilgrim, D. M., et al. (1997). Weight loss in people with Alzheimer's disease: a prospective population based analysis. Br. Med. J. 314, 171-174. doi:10.1136/ bmj.314.7075.178

De Laet, C., Kanis, J., Odén, A., Johanson, H., Johnell, O., Delmas, P., et al. (2005). Body mass index as a predictor of fracture risk: a meta-analysis. Osteoporos. Int. 16, 1330-1338. doi:10.1007/s00198-005-1863-y

Deacon, R. M., and Rawlins, J. N. P. (2005). Hippocampal lesions, species-typical behaviours and anxiety in mice. Behav. Brain Res. 156, 241-249. doi:10.1016/j. bbr.2004.05.027

El Khoury, N., Gratuze, M., Papon, M.-A., Bretteville, A., and Planel, E. (2014). Insulin dysfunction and Tau pathology. Front. Cell. Neurosci. 8:22. doi:10.3389/ fncel.2014.00022

Farooki, A. (2009). Central obesity and increased risk of dementia more than three decades later. Neurology 72, 1030-1031. doi:10.1212/01.wnl.0000343499. 72241.ea

Felson, D. T., Zhang, Y., Hannan, M. T., and Anderson, J. J. (1993). Effects of weight and body mass index on bone mineral density in men and women: the Framingham study. J. Bone Miner. Res. 8, 567-573. doi:10.1002/jbmr. 5650080507

Flegal, K. M., Kit, B. K., Orpana, H., and Graubard, B. I. (2013). Association of all-cause mortality with overweight and obesity using standard body mass index categories: a systematic review and meta-analysis. JAMA 309, 71-82. doi:10.1001/jama.2012.113905

Frederich, R. C., Hamann, A., Anderson, S., Löllmann, B., Lowell, B. B., and Flier, J. S. (1995). Leptin levels reflect body lipid content in mice: evidence for diet-induced resistance to leptin action. Nat. Med. 1, 1311-1314. doi:10.1038/ nm1295-1311

Garcia-Alloza, M., Robbins, E. M., Zhang-Nunes, S. X., Purcell, S. M., Betensky, R. A., Raju, S., et al. (2006). Characterization of amyloid deposition in the APPswe/PS1dE9 mouse model of Alzheimer disease. Neurobiol. Dis. 24, 516-524. doi:10.1016/j.nbd.2006.08.017

Gerlai, R. (1998). A new continuous alternation task in T-maze detects hippocampal dysfunction in mice: a strain comparison and lesion study. Behav. Brain Res. 95, 91-101. doi:10.1016/S0166-4328(97)00214-3

Greco, E. A., Francomano, D., Fornari, R., Marocco, C., Lubrano, C., Papa, V., et al. (2013). Negative association between trunk fat, insulin resistance and skeleton in obese women. World J. Diabetes 4, 31-39. doi:10.4239/wjd.v4.i2.31

Ho, L., Qin, W., Pompl, P. N., Xiang, Z., Wang, J., Zhao, Z., et al. (2004). Dietinduced insulin resistance promotes amyloidosis in a transgenic mouse model of Alzheimer's disease. FASEB J. 18, 902-904. doi:10.1096/fj.03-0978fje

Holloway, W. R., Collier, F. M., Aitken, C. J., Myers, D. E., Hodge, J. M., Malakellis, M., et al. (2002). Leptin inhibits osteoclast generation. J. Bone Miner. Res. 17, 200-209. doi:10.1359/jbmr.2002.17.2.200

Ionova-Martin, S., Wade, J., Tang, S., Shahnazari, M., Ager, I. I. I. J., Lane, N., et al. (2011). Changes in cortical bone response to high-fat diet from adolescence to adulthood in mice. Osteoporos. Int. 22, 2283-2293. doi:10.1007/s00198-0101432-x

Jämsä, T., Jalovaara, P., Peng, Z., Väänänen, H. K., and Tuukkanen, J. (1998). Comparison of three-point bending test and peripheral quantitative computed tomography analysis in the evaluation of the strength of mouse femur and tibia. Bone 23, 155-161. doi:10.1016/S8756-3282(98)00076-3 
Johansson, H., Kanis, J. A., Odén, A., McCloskey, E., Chapurlat, R. D., Christiansen, C., et al. (2014). A Meta-analysis of the association of fracture risk and body mass index in women. J. Bone Miner. Res. 29, 223-233. doi:10.1002/jbmr.2017

Kalmijn, S., Foley, D., White, L., Burchfiel, C. M., Curb, J. D., Petrovitch, H., et al. (2000). Metabolic cardiovascular syndrome and risk of dementia in JapaneseAmerican elderly men. The Honolulu-Asia Aging Study. Arterioscler. Thromb. Vasc. Biol. 20, 2255-2260. doi:10.1161/01.ATV.20.10.2255

Khosla, S., Atkinson, E. J., Riggs, B. L., and Melton, L. J. (1996). Relationship between body composition and bone mass in women. J. Bone Miner. Res. 11, 857-863. doi:10.1002/jbmr.5650110618

Kivipelto, M., Ngandu, T., Fratiglioni, L., Viitanen, M., Kareholt, I., Winblad, B., et al. (2005). Obesity and vascular risk factors at midlife and the risk of dementia and Alzheimer disease. Arch. Neurol. 62, 1556-1560. doi:10.1001/archneur. 62.10 .1556

Leboucher, A., Laurent, C., Fernandez-Gomez, F. J., Burnouf, S., Troquier, L., Eddarkaoui, S., et al. (2013). Detrimental effects of diet-induced obesity on tau pathology are independent of insulin resistance in tau transgenic mice. Diabetes 62, 1681-1688. doi:10.2337/db12-0866

Lee, D.-Y., Na, D. L., Seo, S. W., Chin, J., Lim, S.-J., Choi, D., et al. (2012). Association between cognitive impairment and bone mineral density in postmenopausal women. Menopause 19, 636-641. doi:10.1097/gme.0b013e31823dbec7

Lelovas, P. P., Xanthos, T. T., Thoma, S. E., Lyritis, G. P., and Dontas, I. A. (2008). The laboratory rat as an animal model for osteoporosis research. Comp. Med. 58, 424.

Lieb, W., Beiser, A. S., Vasan, R. S., Tan, Z. S., Au, R., Harris, T. B., et al. (2009). Association of plasma leptin levels with incident Alzheimer disease and MRI measures of brain aging. JAMA 302, 2565-2572. doi:10.1001/jama.2009.1836

Lin, S., Thomas, T., Storlien, L., and Huang, X. (2000). Development of high fat diet-induced obesity and leptin resistance in $\mathrm{C} 57 \mathrm{Bl} / 6 \mathrm{~J}$ mice. Int. J. Obes. Relat. Metab. Disord. 24, 639-646. doi:10.1038/sj.ijo.0801209

Loskutova, N., Honea, R. A., Vidoni, E. D., Brooks, W. M., and Burns, J. M. (2009). Bone density and brain atrophy in early Alzheimer's disease. J. Alzheimers Dis. 18, 777-785. doi:10.3233/JAD-2009-1185

Martin, T. J., and Sims, N. A. (2005). Osteoclast-derived activity in the coupling of bone formation to resorption. Trends Mol. Med. 11, 76-81. doi:10.1016/j. molmed.2004.12.004

McNeilly, A. D., Williamson, R., Balfour, D. J., Stewart, C. A., and Sutherland, C. (2012). A high-fat-diet-induced cognitive deficit in rats that is not prevented by improving insulin sensitivity with metformin. Diabetologia 55, 3061-3070. doi:10.1007/s00125-012-2686-y

McNeilly, A. D., Williamson, R., Sutherland, C., Balfour, D. J., and Stewart, C. A. (2011). High fat feeding promotes simultaneous decline in insulin sensitivity and cognitive performance in a delayed matching and non-matching to position task. Behav. Brain Res. 217, 134-141. doi:10.1016/j.bbr.2010.10.017

Mielke, J. G., Nicolitch, K., Avellaneda, V., Earlam, K., Ahuja, T., Mealing, G., et al. (2006). Longitudinal study of the effects of a high-fat diet on glucose regulation, hippocampal function, and cerebral insulin sensitivity in C57BL/6 mice. Behav. Brain Res. 175, 374-382. doi:10.1016/j.bbr.2006.09.010

Moroz, N., Tong, M., Longato, L., Xu, H., and De La Monte, S. M. (2008). Limited Alzheimer-type neurodegeneration in experimental obesity and type 2 diabetes mellitus. J. Alzheimers Dis. 15, 29-44. doi:10.1096/fj.03-0978fje

Ravn, P., Cizza, G., Bjarnason, N., Thompson, D., Daley, M., Wasnich, R., et al. (1999). Low body mass index is an important risk factor for low bone mass and increased bone loss in early postmenopausal women. J. Bone Miner. Res. 14, 1622-1627. doi:10.1359/jbmr.1999.14.9.1622

Reid, I. R. (2002). Relationships among body mass, its components, and bone. Bone 31, 547-555. doi:10.1016/S8756-3282(02)00864-5

Reid, I. R., Plank, L. D., and Evans, M. C. (1992). Fat mass is an important determinant of whole body bone density in premenopausal women but not in men. J. Clin. Endocrinol. Metab. 75, 779-782. doi:10.1210/jc.75.3.779

Reisel, D., Bannerman, D., Schmitt, W., Deacon, R., Flint, J., Borchardt, T., et al. (2002). Spatial memory dissociations in mice lacking GluR1. Nat. Neurosci. 5, 868-873. doi:10.1038/nn910

Sato, Y., Asoh, T., and Oizumi, K. (1998). High prevalence of vitamin D deficiency and reduced bone mass in elderly women with Alzheimer's disease. Bone 23, 555-557. doi:10.1016/S8756-3282(98)00134-3

Shen, C.-L., Chyu, M.-C., Cao, J. J., and Yeh, J. K. (2013). Green tea polyphenols improve bone microarchitecture in high-fat-diet-induced obese female rats through suppressing bone formation and erosion. J. Med. Food 16, 421-427. doi:10.1089/jmf.2012.0199

Sheu, Y., and Cauley, J. A. (2011). The role of bone marrow and visceral fat on bone metabolism. Curr. Osteoporos. Rep. 9, 67-75. doi:10.1007/s11914-0110051-6

Sienkiewicz, E., Magkos, F., Aronis, K. N., Brinkoetter, M., Chamberland, J. P., Chou, S., et al. (2011). Long-term metreleptin treatment increases bone mineral density and content at the lumbar spine of lean hypoleptinemic women. Metab. Clin. Exp. 60, 1211-1221. doi:10.1016/j.metabol.2011.05.016

Solon-Biet, S. M., McMahon, A. C., Ballard, J. W. O., Ruohonen, K., Wu, L. E., Cogger, V. C., et al. (2014). The ratio of macronutrients, not caloric intake, dictates cardiometabolic health, aging, and longevity in ad libitum-fed mice. Cell Metab. 19, 418-430. doi:10.1016/j.cmet.2014.02.009

Stewart, R., Masaki, K., Xue, Q.-L., Peila, R., Petrovitch, H., White, L. R., et al. (2005). A 32-year prospective study of change in body weight and incident dementia: the Honolulu-Asia Aging Study. Arch. Neurol. 62, 55-60. doi:10.1001/archneur. 62.1 .55

Talbot, K., Wang, H.-Y., Kazi, H., Han, L.-Y., Bakshi, K. P., Stucky, A., et al. (2012). Demonstrated brain insulin resistance in Alzheimer's disease patients is associated with IGF-1 resistance, IRS-1 dysregulation, and cognitive decline. J. Clin. Invest. 122, 1316-1338. doi:10.1172/JCI59903

Tan, Z. S., Seshadri, S., Beiser, A., Zhang, Y., Felson, D., Hannan, M. T., et al. (2005). Bone mineral density and the risk of Alzheimer disease. Arch. Neurol. 62, 107-111. doi:10.1001/archneur.62.1.107

Thomas, T., Gori, F., Khosla, S., Jensen, M. D., Burguera, B., and Riggs, B. L. (1999). Leptin acts on human marrow stromal cells to enhance differentiation to osteoblasts and to inhibit differentiation to adipocytes. Endocrinology 140, 1630-1638. doi:10.1210/en.140.4.1630

Tremollieres, F., Pouilles, J., and Ribot, C. (1993). Vertebral postmenopausal bone loss is reduced in overweight women: a longitudinal study in 155 early postmenopausal women. J. Clin. Endocrinol. Metab. 77, 683-686. doi:10.1210/jcem. 77.3.8370689

Turner, C. (2002). Biomechanics of bone: determinants of skeletal fragility and bone quality. Osteoporos. Int. 13, 97-104. doi:10.1007/s001980200000

Vorhees, C. V., and Williams, M. T. (2006). Morris water maze: procedures for assessing spatial and related forms of learning and memory. Nat. Protoc. 1, 848-858. doi:10.1038/nprot.2006.116

Wada, T., Nakashima, T., Hiroshi, N., and Penninger, J. M. (2006). RANKL-RANK signaling in osteoclastogenesis and bone disease. Trends Mol. Med. 12, 17-25. doi:10.1016/j.molmed.2005.11.007

Weller, I., and Schatzker, J. (2004). Hip fractures and Alzheimer's disease in elderly institutionalized Canadians. Ann. Epidemiol. 14, 319-324. doi:10.1016/j. annepidem.2003.08.005

White, H., Pieper, C., and Schmader, K. (1998). The association of weight change in Alzheimer's disease with severity of disease and mortality: a longitudinal analysis. J. Am. Geriatr. Soc. 46, 1223-1227.

White, H., Pieper, C., Schmader, K., and Fillenbaum, G. (1996). Weight change in Alzheimer's disease. J. Am. Geriatr. Soc. 44, 265-272.

Xia, W.-F., Jung, J.-U., Shun, C., Xiong, S., Xiong, L., Shi, X.-M., et al. (2013). Swedish mutant APP suppresses osteoblast differentiation and causes osteoporotic deficit, which are ameliorated by n-acetyl-1-cysteine. J. Bone Miner. Res. 28, 2122-2135. doi:10.1002/jbmr.1954

Xue, Y., Jiang, L., Cheng, Q., Chen, H., Yu, Y., Lin, Y., et al. (2012). Adipokines in psoriatic arthritis patients: the correlations with osteoclast precursors and bone erosions. PLoS ONE 7:e46740. doi:10.1371/journal.pone. 0046740

Yang, M.-W., Wang, T.-H., Yan, P.-P., Chu, L.-W., Yu, J., Gao, Z.-D., et al. (2011). Curcumin improves bone microarchitecture and enhances mineral density in APP/PS1 transgenic mice. Phytomedicine 18, 205-213. doi:10.1016/j.phymed. 2010.05.011

Yang, P., Jia, B., Ding, C., Wang, Z., Qian, A., and Shang, P. (2009). Whole-body vibration effects on bone before and after hind-limb unloading in rats. Aviat. Space Environ. Med. 80, 88-93. doi:10.3357/ASEM.2368.2009

Yasuda, H., Shima, N., Nakagawa, N., Yamaguchi, K., Kinosaki, M., Mochizuki, S., et al. (1998). Osteoclast differentiation factor is a ligand for osteoprotegerin/osteoclastogenesis-inhibitory factor and is identical to TRANCE/RANKL. Proc. Natl. Acad. Sci. U.S.A. 95, 3597-3602. doi:10.1073/pnas. 95.7.3597 
Yoshimura, N., Suzuki, T., Hosoi, T., and Orimo, H. (2005). Epidemiology of hip fracture in Japan: incidence and risk factors. J. Bone Miner. Res. 23(Suppl.), 78-80. doi:10.1007/BF03026328

Zhou, R., Deng, J., Zhang, M., Zhou, H.-D., and Wang, Y.-J. (2011). Association between bone mineral density and the risk of Alzheimer's disease. J. Alzheimers Dis. 24, 101-108. doi:10.3233/JAD-2010-101467

Conflict of Interest Statement: The authors declare that the research was conducted in the absence of any commercial or financial relationships that could be construed as a potential conflict of interest.

Received: 22 April 2014; accepted: 22 July 2014; published online: 08 August 2014.
Citation: Peng Y, Liu J, Tang Y, Liu J, Han T, Han S, Li H, Hou C, Liu J and Long J (2014) High-fat-diet-induced weight gain ameliorates bone loss without exacerbating $A \beta P P$ processing and cognition in female APP/PS1 mice. Front. Cell. Neurosci. 8:225. doi: 10.3389/fncel.2014.00225

This article was submitted to the journal Frontiers in Cellular Neuroscience.

Copyright (C) 2014 Peng, Liu, Tang, Liu, Han, Han, Li, Hou, Liu and Long. This is an open-access article distributed under the terms of the Creative Commons Attribution License (CC BY). The use, distribution or reproduction in other forums is permitted, provided the original author(s) or licensor are credited and that the original publication in this journal is cited, in accordance with accepted academic practice. No use, distribution or reproduction is permitted which does not comply with these terms. 